\title{
Oxygen-enriched Air Decreases Ventilation during High-intensity Fin-swimming Underwater
}

\section{(c) (1) $(8)$}

\author{
Authors \\ Fabian Möller ${ }^{1} \mathbb{D}^{\mathbb{D}}$, Elena Jacobi ${ }^{1}$, Uwe Hoffmann${ }^{1}$, Thomas Muth ${ }^{2}$, Jochen D. Schipke ${ }^{3}$
}

Affiliations

1 Department of Exercise Physiology, German Sport University Cologne, Cologne, Germany

2 Occupational, Social, Environmental Medicine, HeinrichHeine-Universitat Dusseldorf, Dusseldorf, Germany

3 Research Group Experimenal Surgery, University Hospital Düsseldorf, Dusseldorf, Germany

Key words

SCUBA diving, nitrox, underwater exercise, hyperoxia

accepted 30.06.2021

published online $\quad 16.08 .2021$

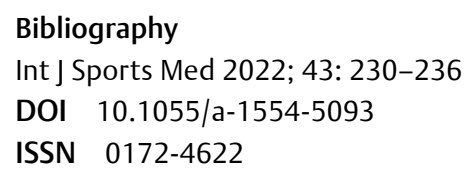

This is an open access article published by Thieme under the terms of the Creative Commons Attribution-NonDerivative-NonCommercial-License, permitting copying and reproduction so long as the original work is given appropriate credit. Contents may not be used for commercial purposes, or adapted, remixed, transformed or built upon. (https://creativecommons. org/licenses/by-nc-nd/4.0/)

Georg Thieme Verlag, Rüdigerstraße 14,

70469 Stuttgart, Germany

\section{Correspondence}

Fabian Möller

Department of Exercise Physiology, German Sport University

Cologne

Am Sportpark Müngersdorf 6

50933 Cologne

Germany

Tel.: 004922149823730 ,

f.moeller@dshs-koeln.de

\begin{abstract}
Oxygen-enriched air is commonly used in the sport of SCUBAdiving and might affect ventilation and heart rate, but little work exists for applied diving settings. We hypothesized that ventilation is decreased especially during strenuous underwater fin-swimming when using oxygen-enriched air as breathing gas. Ten physically-fit divers (age: $25 \pm 4$; 5 females; $67 \pm 113$ open-water dives) performed incremental underwater finswimming until exhaustion at $4 \mathrm{~m}$ water depth with either normal air or oxygen-enriched air $\left(40 \% \mathrm{O}_{2}\right)$ in a double-blind, randomized within-subject design. Heart rate and ventilation were measured throughout the dive and maximum whole blood lactate samples were determined post-exercise. ANOVAs showed a significant effect for the factor breathing gas $\left(F(1,9)=7.52 ; P=0.023 ; \eta_{p}^{2}=0.455\right)$, with a lower ventilation for oxygen-enriched air during fin-swimming velocities of $0.6 \mathrm{~m} \cdot \mathrm{s}^{-1}(\mathrm{P}=0.032)$ and $0.8 \mathrm{~m} \cdot \mathrm{s}^{-1}(\mathrm{P}=0.037)$. Heart rate, lactate, and time to exhaustion showed no significant differences. These findings indicate decreased ventilation by an elevated oxygen fraction in the breathing gas when fin-swimming in shallow-water submersion with high velocity $\left(>0.5 \mathrm{~m} \cdot \mathrm{s}^{-1}\right)$. Applications are within involuntary underwater exercise or rescue scenarios for all dives with limited gas supply.
\end{abstract}

\section{Introduction}

Ventilation $\left(\dot{\mathrm{V}}_{\mathrm{E}}\right)$ is a critical factor for the duration and safety of a dive and might be affected by the inspiratory fraction of oxygen $\left(\mathrm{F}_{1} \mathrm{O}_{2}\right)$ in the breathing gas. This has already been reported in land-based studies for rest and exercise [1-4], but only little work exists for the context of sport-diving with SCUBA (self-contained underwater breathing apparatus) [5-7], where breathing gases with an elevated oxygen content are commonly used [8] and the amount of gas consumed per breath increases with depth. Several diving-specific factors, like exertion during fin-swimming or physiological adaptions underwater might influence this interaction in an applied setting.

Oxygen enriched air (EAN; i. e. inspiratory oxygen fraction $\left(\mathrm{F}_{1} \mathrm{O}_{2}\right)$ above $21 \%$ ) is the second most-used breathing gas besides air in sport-diving, with the main purpose to replace nitrogen $\left(\mathrm{N}_{2}\right)$ with 
oxygen $\left(\mathrm{O}_{2}\right)$. When performing the same dive with EAN instead of air (AIR), $\mathrm{N}_{2}$ tissue saturation and decompression risks are reduced and no-decompression dive-times prolonged [8,9]. One detrimental effect of oxygen-enriched air is oxygen toxicity (i. e. inspiratory oxygen partial pressure $\left.\left(\mathrm{P}_{1} \mathrm{O}_{2}\right)>140 \mathrm{kPa}\right)$, which is known as a limiting factor for $\mathrm{F}_{1} \mathrm{O}_{2}$ in the mix and maximum depth during the dive $[8,10]$. The risk of nitrogen narcosis, which affects responsiveness, well-being, and cognitive performance under high $\mathrm{PN}_{2}$ [11-14], is reduced when diving with EAN. Thus, diving with EAN as a breathing gas has become extremely popular, especially if many repetitive dives are performed.

A higher $\mathrm{F}_{1} \mathrm{O}_{2}$ and $\mathrm{P}_{1} \mathrm{O}_{2}$, respectively, in the lungs (i. e. due to a raised $\mathrm{F}_{1} \mathrm{O}_{2}$ in the breathing gas) results in a higher arterial oxygen partial pressure $\left(\mathrm{P}_{\mathrm{a}} \mathrm{O}_{2}\right)$ and slightly more $\mathrm{O}_{2}$ in the blood. In healthy subjects, this increases solely the concentration of physically dissolved $\mathrm{O}_{2}$, which is marginal compared to hemoglobin-bound $\mathrm{O}_{2}$. However, $\mathrm{O}_{2}$ delivery is a limiting factor for increased workload and especially for transitions in work rate, like during incremental exercise until exhaustion. In those scenarios, an increased $\mathrm{O}_{2}$ delivery (from an increase in $\mathrm{P}_{a} \mathrm{O}_{2}$ ) might be beneficial for $\mathrm{O}_{2}$ diffusion to the muscle and therefore delay the metabolic acidosis from lactate accumulation. This is in line with several studies reporting decreased lactate accumulation during hyperoxic exercise on the bicycle [1520]. Furthermore, the over-proportional increase in $\dot{V}_{E}$, among other things as a result of metabolic acidosis, might be postponed. This can explain higher peak workloads or longer submaximal exercise times $[16,17,21-23]$. Also, a lower perceived exertion was stated for hyperoxic exercise [24, 25].

Peripheral arterial chemoreceptors, like in the carotid bodies, regulate $\dot{\mathrm{V}}_{\mathrm{E}}$ by monitoring $\mathrm{PO}_{2}, \mathrm{PCO}_{2}$, and $\mathrm{pH}$. Whereas hypoxemia leads to an increase of $\dot{V}_{E}$ during rest, hyperoxia (i. e. higher $\mathrm{P}_{\mathrm{a}} \mathrm{O}_{2}$ ) attenuates the sensitivity of those receptors [1, 4, 26]. Furthermore, a lower heart rate (HR) was observed in hyperoxia during rest $[27,28]$ as a result of enhanced vascular resistance and during exercise [3], where a reduced sympathetic activation was suspected as the modulating factor at steady-state exercise intensities.

In submersion studies with moderate exercise on a bicycle ergometer, a lower $\dot{\mathrm{V}}_{\mathrm{E}}$ was observed at depth (470 kPa ambient pressure) with a $\mathrm{P}_{1} \mathrm{O}_{2}$ of $21 \mathrm{kPa}$ [5], which suggests the sole influence of submersion, and under hyperoxia $\left(175 \mathrm{kPa}_{\mathrm{P}} \mathrm{O}_{2}\right)[5,6]$. These studies observed no effects on $\dot{\mathrm{V}}_{\mathrm{E}}$ between $70 \mathrm{kPa}$ and $130 \mathrm{kPa} \mathrm{P}_{\mathrm{I}} \mathrm{O}_{2}$, which might be attributed to the counteracting effects of breathing gas density at depth. However, most findings so far are from cycle ergometer experiments in the laboratory or a pressure chamber and did not consider specific sport-diving aspects like exercise modality (i.e. fin-swimming vs. cycling), the body-position in the water (i. e. upright vs. supine), or immersion with potential influences on physiological reactions such as metabolism, blood shift, and breathing resistance. In combination with an increased $\mathrm{F}_{1} \mathrm{O}_{2}$ in the breathing gas (i. e. $56 \mathrm{kPa}$ at $4 \mathrm{~m}$ water depth), exercise modality might affect $\mathrm{O}_{2}$ consumption and whole blood lactate production, at least in transient phases, and therefore the respiratory drive. In turn, factors like $\dot{V}_{E}, H R$, perceived exertion, and time to exhaustion (TTE) might be affected in an applied context during incremental exercise. Therefore, former findings need verification in an applied field setting for sport diving.
In this study, we investigated the effects of either AIR $\left(21 \% \mathrm{O}_{2}\right)$ or EAN $\left(40 \% \mathrm{O}_{2}\right)$ as breathing gas on $\dot{\mathrm{V}}_{\mathrm{E}}$, $\mathrm{HR}$, lactate concentration [ $\left.\mathrm{Lac}^{-}\right]$, and TTE during underwater incremental fin-swimming. We hypothesized, that $\dot{V}_{E}$ and $H R$ are lowered for EAN at given fin-swimming speeds. Additionally, lower [ $\left.\mathrm{Lac}^{-}\right]$after exhaustive underwater fin-swimming was expected.

\section{Materials and Methods}

\section{Participants}

An a priori sample size calculation ( $G^{*}$ Power 3.1.9.2) demanded a total sample size of 10 participants to obtain an effect size $f=0.5$ and power of $1-\beta=0.80$ with a mixed design and a significance level of $\alpha<0.05$. Eleven healthy, young, and physically-fit sport students participated in the study (see $>$ Table 1). One female participant did not complete the velocity of $0.8 \mathrm{~m} \cdot \mathrm{s}^{-1}$ for both conditions and was excluded from the analysis ( $N=10 ; 25 \pm 4$ years (mean $\pm S D) ; 5$ females). Each participant performed two test conditions with incremental underwater fin-swimming until exhaustion, breathing either AIR or EAN. All tests were conducted in an indoor pool $(20 \times 20 \times 5$ meters $)$ in approximately $4 \mathrm{~m}$ water depth. A valid medical examination for diving and diving experience of five or more open-water dives was mandatory for participation. All divers were informed about the purpose and design of the study and signed an informed consent form before participation. Termination of participation was possible at all times without reasoning. An ethics committee, following the declaration of Helsinki, approved the study [29].

\section{Study Design}

All participants performed two test conditions in a crossover, randomized and double-blind design with a mandatory interval of 2-7 days to ensure full physical recovery. Neither the test conductor nor the participants knew which gas was used in which test. Only the study supervisor knew the organization of test conditions and gas logistics. In one condition, the breathing gas was normal air (AIR), and in the other oxygen-enriched air $\left(40 \% \mathrm{O}_{2}\right.$, enriched air Nitrox: EAN). Test conditions differed solely by the breathing gas (AIR, EAN). The diving gear was provided and consisted of a $3 \mathrm{~mm}$ wetsuit, a $10 \mathrm{~L}$ steel tank, a commercially available buoyancy control device (BCD), a breathing regulator, mask and fins.

The fit2dive-test's underwater exercise parcours [30] was utilized for incremental fin-swimming. The test was developed to enable specific exercise testing for sport divers, taking into account specific locomotion, equipment-induced water drag, and fin-swimming technique. The parcours consisted of a $50 \mathrm{~m}$-long rope that was anchored to the bottom of the pool in the shape of a hexagon. Checkpoints were marked with a buoy to allow for self-controlled fin-swimming velocity with a marching-table and stopwatch. After a mandatory round of slow fin-swimming for familiarization, participants then started swimming under the supervision of the test conductor. Fin-swimming velocity was increased in $150 \mathrm{~s}$-long steps of $0.4 \mathrm{~m} \cdot \mathrm{s}^{-1}, 0.6 \mathrm{~m} \cdot \mathrm{s}^{-1} 0.8 \mathrm{~m} \cdot \mathrm{s}$ 1 and $1.0 \mathrm{~m} \cdot \mathrm{s}^{-1}$. The test ended if two consecutive checkpoints could not be reached according to the marching chart. Participants then surfaced together with the test conductor and stated their rating of perceived exertion (RPE) on a scale ranging from "very light" (6) to "full exertion" (20) [31]. 
- Table 1 Table shows individual values, mean values, and standard deviation for the number of open-water dives, overall and specific fin-swimming self-stated fitness level, and weekly training hours for all participants $(\mathrm{N}=10)$.

\begin{tabular}{|c|c|c|c|c|c|c|}
\hline $\begin{array}{l}\text { Age } \\
\text { [years] }\end{array}$ & $\begin{array}{l}\text { Weight } \\
{[\mathrm{kg}]}\end{array}$ & $\begin{array}{l}\text { Height } \\
{[\mathrm{cm}]}\end{array}$ & $\begin{array}{l}\text { Open-water } \\
\text { dives }\end{array}$ & $\begin{array}{l}\text { physical training } \\
\text { [h per week] }\end{array}$ & $\begin{array}{l}\text { overall fitness level } \\
\text { [self-stated] }\end{array}$ & $\begin{array}{l}\text { fin-swimming fitness } \\
\text { level [self-stated] }\end{array}$ \\
\hline 23 & 67 & 175 & 72 & 12 & good & good \\
\hline 25 & 78 & 173 & 12 & 10 & medium & medium \\
\hline 24 & 70 & 170 & 35 & 3 & medium & medium \\
\hline 23 & 82 & 185 & 25 & 3 & good & good \\
\hline 22 & 61 & 168 & 25 & 1 & medium & medium \\
\hline 21 & 68 & 180 & 14 & 6 & good & good \\
\hline 22 & 55 & 167 & 400 & 10 & good & good \\
\hline 23 & 78 & 177 & 65 & 10 & good & good \\
\hline 27 & 82 & 176 & 5 & 5 & good & medium \\
\hline 36 & 72 & 178 & 14 & 2 & medium & bad \\
\hline 25 & 71 & 175 & 67 & 6 & & \\
\hline 4 & 8 & 5 & 113 & 4 & & \\
\hline
\end{tabular}

\section{Measurements}

Process during incremental exercise was tracked by the test conductor. The maximum time to exhaustion was noted for every participant and condition. HR and tank pressure was recorded with a heartratebelt and pressure transmitter, respectively. Recordings were made every $4 \mathrm{~s}$ and stored on the dive computer for later analysis. Before the start of physical exercise , a 3-min HR-baseline measurement was recorded in the supine position at $5 \mathrm{~m}$ water depth.

Whole blood [ $\left.\mathrm{Lac}^{-}\right]$was determined from earlobe blood samples once before submersion (i. e. after 30 min of rest; baseline) and five times with one-minute intervals after exercise, the first sample taken immediately after the termination of exercise and surfacing with the participants (i. e. approx. $15 \mathrm{~s}$ after exercise). The maximum lactate concentration $\left[\mathrm{Lac}^{-}\right]_{\max }$ was determined as the highest value out of the five samples taken after exercise. The samples were stored cooled and analyzed the same day in the laboratory.

\section{Data Processing}

$\dot{V}_{E}$ was calculated for ambient pressure using tank-pressure and depth recordings from the diving computer. In our formula, $\dot{V}_{\mathrm{E}}$ $\left[\mathrm{L} \cdot \mathrm{min}^{-1}\right]$ is the amount of gas consumed per minute, $\Delta \mathrm{P}_{\text {tank }}[\mathrm{kPa}]$ is the difference in tank pressure throughout $40 \mathrm{~s}, V_{\text {tank }}[L]$ is the volume of the tank, and $\mathrm{P}_{\text {depth }}[\mathrm{kpa}]$ is the mean of depth reading (recorded every $4 \mathrm{~s}$ ) throughout $40 \mathrm{~s}$ multiplied by $10 \mathrm{kPa}+100 \mathrm{kPa}$. Means for $\dot{V}_{E}$ and $H R$ were determined during the last 20 s of every velocity.

$\dot{\mathrm{V}}_{\mathrm{E}}=\Delta \mathrm{P}_{\text {tank }} \times \mathrm{V}_{\text {tank }} \times \mathrm{P}_{\text {depth }}{ }^{-1}$

The second ventilatory threshold (VT2) was estimated for both conditions by three experienced evaluators as the point of over-proportional increase of $\dot{V}_{E}$ in relation to HR (see $>$ Fig. 1), marking rapid lactate increase and hyperventilation [32]. VT2 was utilized to gain information on the participants' metabolism during exercise, as we could not perform spiroergometric measurements or take lactate samples underwater.
- Table 2 shows means and standard deviations for $\dot{V}_{E}, H R$, and time at VT2 for the three independent estimations. Figures show means and $95 \%$ confidence intervals. Mean values for $\dot{V}_{E}$ and $H R$ throughout the exercise were calculated over the last $20 \mathrm{~s}$ at rest and for every fin-swimming velocity.

\section{Statistics}

Using SPSS statistics 25 (IBM, USA), all variables were checked for a violation of normal distribution using the Shapiro-Wilks test. Alpha was set to 0.05 . Two-way ANOVAs with repeated measures on the factors gas (AIR, EAN) and velocity (Rest, $0.4 \mathrm{~m} \cdot \mathrm{s}^{-1}, 0.6 \mathrm{~m}$. $\mathrm{s}^{-1}$, and $0.8 \mathrm{~m} \cdot \mathrm{s}^{-1}$ ) were calculated for $\mathrm{HR}, \dot{\mathrm{V}}_{\mathrm{E}}$ and [Lac-]. Multiple mean value comparisons according to Bonferroni and one-tailed pairwise comparisons were used to investigate significant results. The correlation between $\left[\mathrm{Lac}^{-}\right]_{\max }$ and TTE was investigated using the correlation coefficient from Spearman. For main-effects, effectsizes were estimated using partial eta squared $\left(\eta_{p}^{2}\right)$, where values $=0.01$ indicate a small effect, values $=0.06$ a medium effect, and values $=0.14$ a large effect. For post-hoc comparisons, Cohen's $\mathrm{d}$ was computed as the quotient from the difference between two means and the mean standard deviation, where values between 0.2 and 0.5 indicate a small effect, values between 0.5 and 0.8 indicate a medium effect, and values $>0.8$ indicate a large effect [33].

\section{Results}

The analysis of $\dot{V}_{E}$ produced significant main effects for the factor gas $\left(F(1,9)=7.52 ; P=0.023 ; \eta^{2}=0.455\right)$ and velocity $(F(1.25$, $\left.11.21)=39.59 ; P<0.001 ; \eta_{p}^{2}=0.815\right)$. An interaction effect for gas * velocity could not be found $(F(1.51,13.52)=2.52 ; P=0.126$; $\left.\eta_{p}^{2}=0.220\right)$. Post-hoc, values for EAN were significantly lower compared to AIR during the velocities of $0.6 \mathrm{~m} \cdot \mathrm{s}^{-1}(\mathrm{P}=0.032 ; \mathrm{d}=1.02)$ and $0.8 \mathrm{~m} \cdot \mathrm{s}^{-1}(\mathrm{P}=0.037 ; \mathrm{d}=0.47)$. Participants reached $\mathrm{VT} 2$ at a similar time during exercise (AIR, EAN) with no significant differences for $\mathrm{HR}$ and $\dot{\mathrm{V}}_{\mathrm{E}}$ (see $>$ Fig. 2 and $>$ Table $\mathbf{1}$ ).

$H R$ showed a significant main effect for velocity $(F(1.75$, $\left.15.74)=154.27 ; P<0.001 ; \eta^{2}=0.945\right)$, but not for $\operatorname{gas}(F(1,9)=0.691$; $\left.P=0.427 ; \eta^{2}=0.071\right)$ or gas * velocity $(F(1.58,14.18)=0.453 ; P=0.599$; 


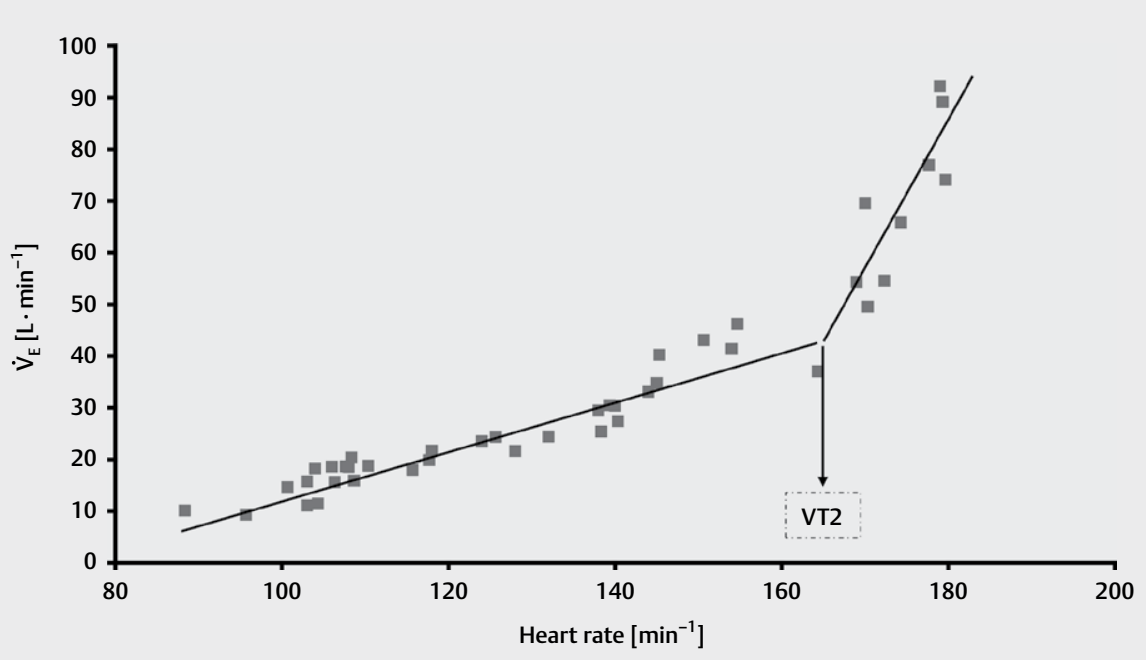

- Fig. 1 Data shows the determination of the ventilatory threshold at the disproportional increase of Ventilation $\left(\dot{\mathrm{V}}_{\mathrm{E}}\right)$ in ratio to heart rate (HR). Example of one subject.

- Table 2 Mean values for ventilation $\left(\dot{\mathrm{V}}_{\mathrm{E}}[\mathrm{L}]\right)$ and heart rate $\left(\mathrm{HR}\left[\mathrm{min}^{-1}\right]\right)$ were calculated for the last 20 seconds of every velocity (Rest, $0.4,0.6$, and $\left.0.8 \mathrm{~m} \cdot \mathrm{s}^{-1}\right)$. The maximum whole blood lactate $\left[\mathrm{Lac}^{-}\right]_{\max }\left[\mathrm{mmol} \cdot \mathrm{L}^{-1}\right]$ was the highest lactate sample taken after incremental exercise. The maximum time to exhaustion (TTE) was the time accomplished during incremental exercise. The rating of perceived exertion (RPE) was stated directly after exercise. $\mathrm{HR}, \dot{\mathrm{V}}_{\mathrm{E}}$, and time for ventilatory threshold (VT2) were estimated by three experienced evaluators. Table shows means \pm standard deviation. ${ }^{*} \mathrm{P}<0.05$ for comparisons of breathing gases (AIR vs. EAN).

\begin{tabular}{|c|c|c|c|c|}
\hline & \multicolumn{2}{|c|}{ Variable } & \multirow{2}{*}{$\begin{array}{l}\text { EAN [40\% } \\
\left.\mathbf{O}_{2}\right] \\
1.31 \pm 0.5\end{array}$} & \multirow{2}{*}{$\begin{array}{l}\text { AIR [21\% } \\
\left.\mathbf{O}_{2}\right] \\
1.43 \pm 0.6\end{array}$} \\
\hline \multirow{3}{*}{ Rest } & {$\left[\mathrm{Lac}^{-}\right]$} & {$\left[\mathrm{mmol} \cdot \mathrm{L}^{-1}\right]$} & & \\
\hline & $\mathrm{HR}$ & [bpm] & $96 \pm 12$ & $96 \pm 13$ \\
\hline & $\dot{\mathrm{V}}_{\mathrm{E}}$ & {$\left[\mathrm{L} \cdot \mathrm{min}^{-1}\right]$} & $17 \pm 7$ & $18 \pm 6$ \\
\hline \multirow{2}{*}{$0.4\left[\mathrm{~m} \cdot \mathrm{s}^{-1}\right]$} & $\mathrm{HR}$ & [bpm] & $111 \pm 8$ & $108 \pm 14$ \\
\hline & $\dot{\mathrm{V}}_{\mathrm{E}}$ & {$\left[\mathrm{L} \cdot \mathrm{min}^{-1}\right]$} & $22 \pm 4$ & $22 \pm 6$ \\
\hline \multirow{2}{*}{$0.6\left[\mathrm{~m} \cdot \mathrm{s}^{-1}\right]$} & $\mathrm{HR}$ & [bpm] & $145 \pm 14$ & $140 \pm 19$ \\
\hline & $\dot{\mathrm{V}}_{\mathrm{E}}^{*}$ & {$\left[\mathrm{~L} \cdot \mathrm{min}^{-1}\right]$} & $35 \pm 7$ & $44 \pm 12$ \\
\hline \multirow{2}{*}{$0.8\left[\mathrm{~m} \cdot \mathrm{s}^{-1}\right]$} & $\mathrm{HR}$ & [bpm] & $171 \pm 10$ & $170 \pm 14$ \\
\hline & $\dot{\mathrm{V}}_{\mathrm{E}}^{*}$ & {$\left[\mathrm{~L} \cdot \mathrm{min}^{-1}\right]$} & $63 \pm 26$ & $74 \pm 25$ \\
\hline \multirow{3}{*}{ VT2 } & $\mathrm{HR}$ & [bpm] & $149 \pm 19$ & $153 \pm 13$ \\
\hline & $\dot{\mathrm{V}}_{\mathrm{E}}$ & {$\left[\mathrm{L} \cdot \mathrm{min}^{-1}\right]$} & $34 \pm 10$ & $38 \pm 10$ \\
\hline & Time & {$[\mathrm{s}]$} & $327 \pm 74$ & $344 \pm 83$ \\
\hline \multirow{3}{*}{ Max } & RPE & [a.u.] & $16 \pm 2$ & $15.9 \pm 1.7$ \\
\hline & TTE & {$[\mathrm{s}]$} & $480 \pm 62$ & $480 \pm 71$ \\
\hline & {$\left[\mathrm{Lac}^{-}\right]_{\max }$} & {$\left[\mathrm{mmol} \cdot \mathrm{L}^{-1}\right]$} & $6.9 \pm 1.2$ & $7.1 \pm 1.4$ \\
\hline
\end{tabular}

$\left.\eta_{\mathrm{p}}^{2}=0.048\right) .\left[\mathrm{Lac}^{-}\right]$did not show any significant variations between $\mathrm{EAN}$ and $\operatorname{AIR}\left(F(1,9)=0.16 ; P=0.699 ; \eta^{2}=0.017\right.$, see $>$ Fig. 3). No difference for TTE or RPE during exercise was found between conditions $\left(F(1,9)=0.037 ; P=0.852 ; \eta_{p}^{2}=0.004\right.$, see $>$ Table 2$)$.

For AIR, Spearman correlation coefficient showed a significant correlation for [ $\left.\mathrm{Lac}^{-}\right]$and TTE $\left(r_{s}=0.638 ; P=0.047\right)$. A correlation with EAN showed no significant effects $\left(r_{s}=0.329 ; P=0.353\right)$.

\section{Discussion}

Our results show a significantly lower $\dot{V}_{E}$ with EAN for the fin-swimming velocities of $0.6 \mathrm{~m} \cdot \mathrm{s}^{-1}$ and $0.8 \mathrm{~m} \cdot \mathrm{s}^{-1}$ in shallow underwater settings compared to AIR. Surprisingly, [ $\left.\mathrm{Lac}^{-}\right]_{\max }$ after exercise did not show any significant differences between AIR and EAN. We observed no differences or correlations for HR, TTE, or the ventilatory threshold.

Thus, it can be speculated why the effect of a lower $\dot{\mathrm{V}}_{\mathrm{E}}$ only shows for high velocities. In normobaric conditions, hemoglobin in arterial blood is typically saturated for $97 \%$ or higher. Whereas increased $\mathrm{PO}_{2}$ has no relevant effects on hemoglobin saturation, the concentration of physically dissolved oxygen increases linearly according to the ambient pressure (Henry's law) [34]. For normobaric conditions, the dissolved $\mathrm{O}_{2}$ concentration for an alveolar $\mathrm{PO}_{2}$ of 15 kilopascal $(\mathrm{kPa})$ can be approximated to $3 \mathrm{~mL} \cdot \mathrm{L}^{-1}$ for AIR and $6.8 \mathrm{~mL} \cdot \mathrm{L}^{-1}$ for EAN (i. e. $34 \mathrm{kPa}$ alveolar $\mathrm{PO}_{2}$ ), respectively, when assuming a physical solubility for $\mathrm{O}_{2}$ of $0.2 \mathrm{~mL}(\mathrm{~L} \cdot \mathrm{kPa})^{-1}$ [35]. The inspiratory $\mathrm{P}_{1} \mathrm{O}_{2}$ for EAN in the present study results in more than two times the physically dissolved $\mathrm{O}_{2}$ in the arterial blood $\left[\mathrm{O}_{2}\right.$ art $]$ when compared to AIR (see $>$ Table. 3). At $25 \mathrm{~m}$, which is a common water depth in sport diving, breathing EAN leads to an $\mathrm{O}_{2}$ art of $26.8 \mathrm{~mL} \cdot \mathrm{L}^{-1}$.

We assume that during rest and low velocities (i. e. $0.4 \mathrm{~m} \cdot \mathrm{s}^{-1}$ ), the muscles' oxygen demand is sufficiently covered. With increasing exercise intensity, the delay of cardiovascular adaptations to the working muscles increased $\mathrm{O}_{2}$-demand then creates a local oxygen deficit [36, 37]. An increased $\mathrm{O}_{2}$ supply and the accompanying greater amount of oxygen in the blood increase oxygen uptake $\left(\dot{\mathrm{V}}_{2}\right)$, and could enhance the diffusion of oxygen to the muscle [20]. As a result, additional glycogen oxidation could attenuate the accumulation of lactate and respiratory acidosis [3, 26, 37]. Hyperoxia (e.g. hyperbaric conditions underwater) might reduce the amount of metabolic anaerobic glycolysis at least during transient phases after increased exercise intensity [38], thus reducing lactate production and maintaining a higher ph-value with a slower 


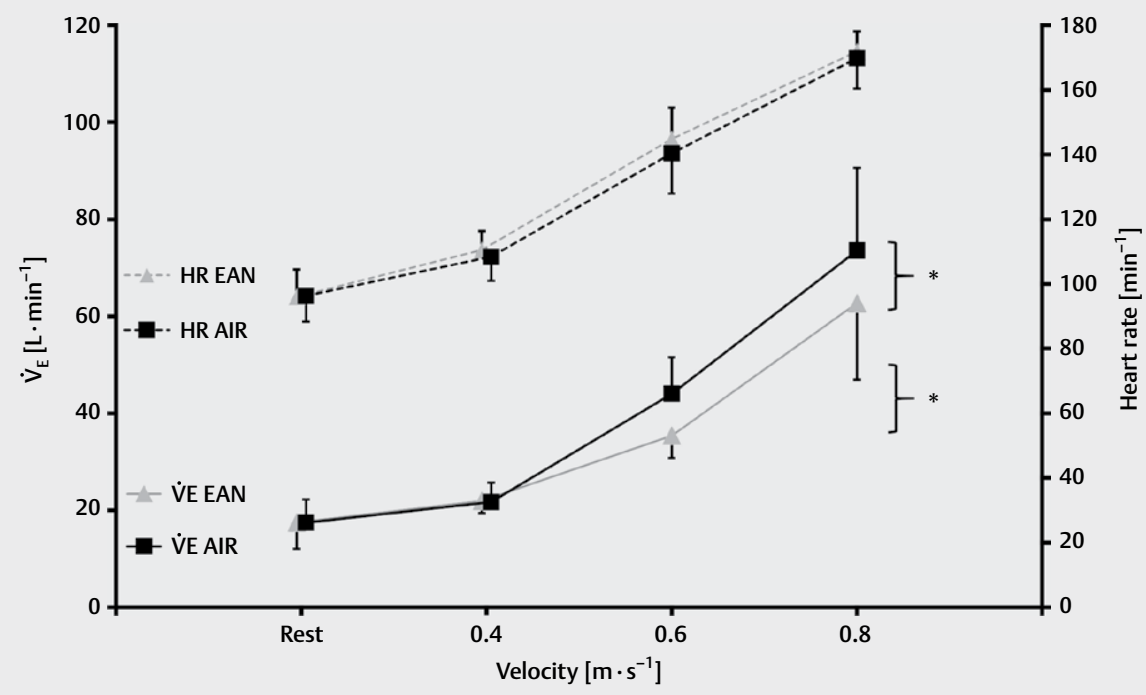

- Fig. 2 The $X$-axis depicts rest and the velocities $0.4,0.6$, and $0.8 \mathrm{~m} \cdot \mathrm{s}^{-1}$. Means and $95 \%$ confidence intervals are shown for heart rate (upper two

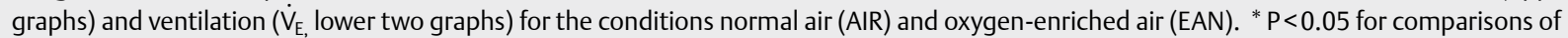
breathing gases (AIR vs. EAN).

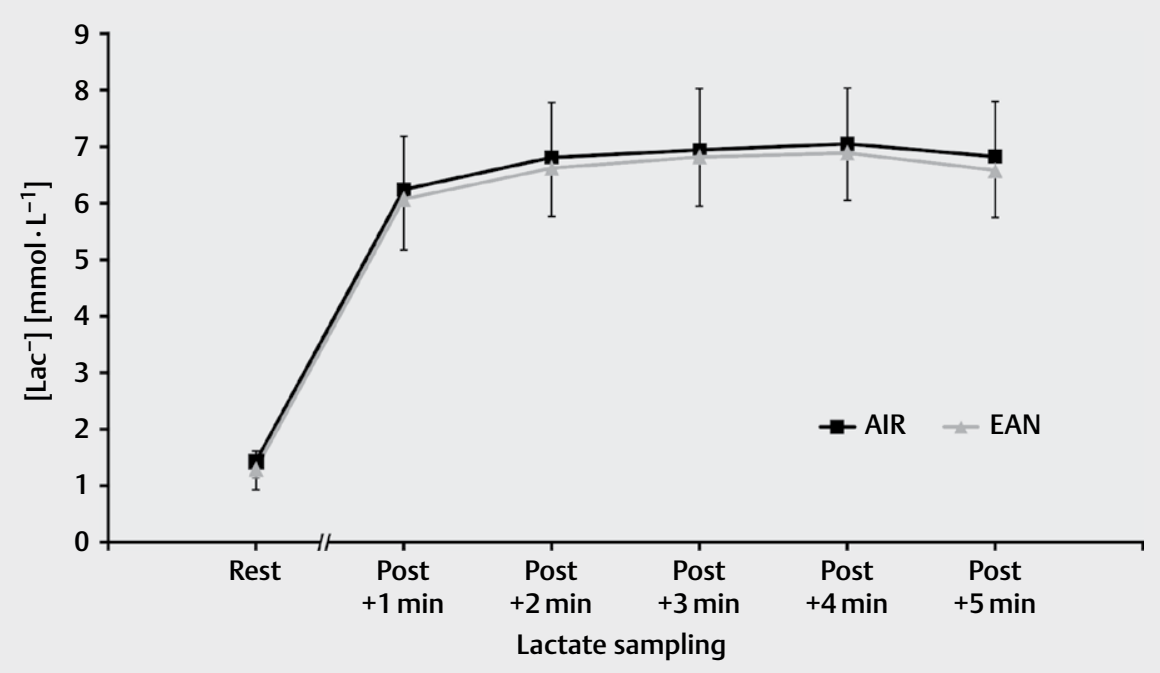

Fig. 3 Means and 95\% confidence intervals for samples of whole blood lactate concentrations [ Lac $^{-}$] from the earlobe. Samples were taken once before exercise (Rest) and every minute for five times directly following incremental exercise (Post $+x$ min).

increase in $\dot{V}_{E}$ from an alleviated respiratory drive [26, 38]. This seems especially relevant with a decreased oxygen deficit during work rate transitions and high-intensity exercise [16, 36, 38], where the acceleration of $\dot{\mathrm{O}}_{2}$ kinetics must be assumed [38, 39]. These metabolic adaptions and their influence on VT2 could be backed up in future studies involving spirometric measurements.

It should be noted that other studies reported decreases in $\dot{\mathrm{V}}_{\mathrm{E}}$ during hyperoxic exercise accompanied by a decrease in blood lactate [20,40-42], which is inconsistent with our data (see [37] for a review). Differences in [ $\left.\mathrm{Lac}^{-}\right]$might become clearer with measurements conducted during exercise, which was not possible in this experimental setup. In this study, maximum values measured after exercise might not reflect the metabolic state during exercise. Some authors also emphasized the relevance of individual physical fitness and exercise intensity [20] as well as recruited muscle mass [43] on lactate production during hyperoxic exercise. In line with our findings, Pederson et al. reported only non-significantly lower [ $\left.\mathrm{LaC}^{-}\right]$ during submaximal exercise involving small muscle groups [44]. Although these differences between underwater fin-swimming and modalities like running and cycling might explain our findings, new technologies for continuous underwater lactate measurements should be employed in future studies.

TTE and RPE, which did not differ between conditions in our study, most likely depend on exercise modality (i. e. running vs. cy- 
- Table 3 Relation of inspiratory and alveolar oxygen partial pressure $\left(\mathrm{PO}_{2}[\mathrm{kPa}]\right)$ and the related arterial $\mathrm{O}_{2}$ concentration $\left[\mathrm{O}^{2}\right.$ art $]$ for $\operatorname{AIR}(21 \%$ $\left.\mathrm{O}_{2}\right)$ and EAN $\left(40 \% \mathrm{O}_{2}\right)$ as breathing gases. Data were calculated for normobaric (100 kPa) and hyperbaric (140 kPa and $350 \mathrm{kPa}$, respectively) underwater conditions.

\begin{tabular}{|c|c|c|c|c|c|}
\hline & & \multicolumn{2}{|c|}{$\operatorname{EAN}\left[40 \% \mathrm{O}_{2}\right]$} & \multicolumn{2}{|c|}{ AIR $\left[21 \% O_{2}\right]$} \\
\hline & & $\begin{array}{l}\mathrm{PO}_{2} \\
{[\mathrm{kPa}]}\end{array}$ & $\begin{array}{l}{\left[\mathrm{O}_{\text {2art }}\right]} \\
{\left[\mathrm{mL} \cdot \mathrm{L}^{-1}\right]}\end{array}$ & $\begin{array}{l}\mathrm{PO}_{2} \\
{[\mathrm{kPa}]}\end{array}$ & $\begin{array}{l}{\left[\mathrm{O}_{2 \mathrm{art}}\right]} \\
{\left[\mathrm{mL} \cdot \mathrm{L}^{-1}\right]}\end{array}$ \\
\hline \multirow{2}{*}{$\begin{array}{l}\text { normobaric } \\
\text { [100 kPa] }\end{array}$} & inspiratory & 40 & \multirow{2}{*}{6.8} & 21.0 & \multirow{2}{*}{3.0} \\
\hline & alveolar & 34 & & 15.0 & \\
\hline \multirow{2}{*}{$\begin{array}{l}\text { hyperbaric } \\
\text { [underwater] } \\
{[140 \mathrm{kPa}]}\end{array}$} & inspiratory & 56 & \multirow[b]{2}{*}{10.0} & 29.4 & \multirow[b]{2}{*}{4.7} \\
\hline & alveolar & 50 & & 23.4 & \\
\hline \multirow{2}{*}{$\begin{array}{l}\text { hyperbaric } \\
\text { [underwater] } \\
\text { [350 kPa] }\end{array}$} & inspiratory & 140 & \multirow[b]{2}{*}{26.8} & 73.5 & \multirow{2}{*}{13.5} \\
\hline & alveolar & 134 & & 67.5 & \\
\hline
\end{tabular}

cling), the applied exercise test (i. e. time trials, constant work rate, incremental exercise), exercise duration, and $\mathrm{F}_{1} \mathrm{O}_{2}$ [37]. Some studies reported a prolonged TTE and RPE in hyperoxic settings $[3,23,37,45]$, whereas Peeling et al. observed influences on RPE only with $\mathrm{F}_{1} \mathrm{O}_{2}>100 \mathrm{kPa}$ [25]. In the present study, work rate stages during incremental exercise were defined by velocity rather than power. In contrast to exercise in the laboratory, water-resistance underwater increases exponentially with velocity, thus making an increase in work rate more difficult, especially during high-intensity exercise. The absence of a prolonged TTE was likely dependent on the individual fin-swimming efficiency and leg strength, and therefore individual physical exhaustion was not reached in every test. Future studies should investigate these effects for different water depths, $\mathrm{PO}_{2}$ and prolonged constant work rates.

\section{Conclusions}

Our results reveal a significantly lower $\dot{\mathrm{V}}_{\mathrm{E}}$ for high-intensity fin swimming (i. e. $\geq 0.6 \mathrm{~m} \cdot \mathrm{s}^{-1}$ ) in shallow water in hyperoxia $\left(\mathrm{P}_{\mathrm{l}} \mathrm{O}_{2}=56 \mathrm{kPa}\right.$ ) compared to normal air. No effects were observed for [ $\left.\mathrm{Lac}^{-}\right]_{\max }$, TTE, and RPE. Hyperoxic gases like EAN40 $\left(=40 \% \mathrm{O}_{2}\right)$ are frequently used by sport divers and gas consumption plays a major role in planning and executing dives with a limited gas supply. During a dive at $20 \mathrm{~m}$ water depth, our results would suggest $270 \mathrm{~L}$ less gas consumed for $10 \mathrm{~min}$ of fin-swimming at $0.6 \mathrm{~m} \cdot \mathrm{s}^{-1}$, when using EAN instead of normal air (i.e. 27 bar or 400 psi less in a $10 \mathrm{~L}$ dive tank). This velocity can be considered reasonable when swimming against a current. Although exercise intensity, modality, ambient pressure (i.e. increased $\mathrm{P}_{1} \mathrm{O}_{2}$ at depth), and accompanying increased breathing gas density must be considered as modulating factors, the use of hyperoxic gases in sport diving could lower $\dot{V}_{E}$ in shallow water contexts and therefore increase the duration or safety of the dive with higher gas reserves.

\section{Declaration of Helsinki statement}

This study followed the rules of the declaration of Helsinki.

\section{Acknowledgements}

This work was supported by the Gesellschaft für Tauch- und Überdruckmedizin (GTÜM). We thank the Diving School "Magic Factory" in Wuppertal, Germany for gas support.

\section{Conflict of interest}

The authors declare that they have no conflict of interest.

\section{References}

[1] Forster HV, Haouzi P, Dempsey JA. Control of breathing during exercise. Compr Physiol 2012; 2: 743-777

[2] Andersson JPA, Linér MH, Fredsted A et al. Cardiovascular and respiratory responses to apneas with and without face immersion in exercising humans. J Appl Physiol (1985) 2002; 96: 1005-1010

[3] Ulrich S, Hasler ED, Müller-Mottet S et al. Mechanisms of improved exercise performance under hyperoxia. Respiration 2017; 93: 90-98

[4] Dejours P. Chemoreflexes in breathing. Physiol Rev 1962; 42: 335-358

[5] Peacher DF, Pecorella SRH, Freiberger ]J et al. Effects of hyperoxia on ventilation and pulmonary hemodynamics during immersed prone exercise at 4.7 ATA: Possible implications for immersion pulmonary edema. J Appl Physiol (1985) 2010; 109: 68-78

[6] Fraser JAV, Peacher DF, Freiberger J] et al. Risk factors for immersion pulmonary edema: Hyperoxia does not attenuate pulmonary hypertension associated with cold water-immersed prone exercise at 4.7 ATA. J Appl Physiol (1985) 2011; 110: 610-618

[7] Zenske A, Kähler W, Koch A et al. Does oxygen-enriched air better than normal air improve sympathovagal balance in recreational divers? An open-water study. Res Sports Med 2020, 28, 397-412

[8] Brebeck AK, Deussen A, Range $U$ et al. Beneficial effect of enriched air nitrox on bubble formation during scuba diving. An open-water study. J Sports Sci 2018; 36: 605-612

[9] Mitchell S], Doolette DJ. Recreational technical diving part 1: An introduction to technical diving methods and activities. Diving Hyperb Med 2013; 43: 86-93

[10] Fock A, Harris R, Slade M. Oxygen exposure and toxicity in recreational technical divers. Diving Hyperb Med 2013; 43: 67-71

[11] Germonpré P, Balestra C, Hemelryck W et al. Objective vs. subjective evaluation of cognitive performance during 0.4-MPa dives breathing air or nitrox. Aerosp Med Hum Perform 2017; 88: 469-475

[12] Balestra C, Lafère P, Germonpré P. Persistence of critical flicker fusion frequency impairment after a $33 \mathrm{mfw}$ SCUBA dive: Evidence of prolonged nitrogen narcosis? Eur J Appl Physiol 2012; 112: 4063-4068

[13] Steinberg F, Doppelmayr M. Executive functions of divers are selectively impaired at 20-meter water depth. Front Psychol 2017; 8: 1000

[14] Rocco M, Pelaia P, Di Benedetto P et al. Inert gas narcosis in scuba diving, different gases different reactions. Eur J Appl Physiol 2019; 119 : 247-255

[15] Fagraeus L, Karlsson J, Linnarsson D et al. Oxygen uptake during maximal work at lowered and raised ambient air pressures. Acta Physiol Scand 1973; 87: 411-421

[16] Linnarsson D, Karlsson J, Fagraeus L et al. Muscle metabolites and oxygen deficit with exercise in hypoxia and hyperoxia. J Appl Physiol 1974; 36: 399-402

[17] Noakes TD, Peltonen JE, Rusko HK. Evidence that a central governor regulates exercise performance during acute hypoxia and hyperoxia. J Exp Biol 2001; 204: 3225-3234 
[18] Welch HG, Mullin JP, Wilson GD et al. Effects of breathing O2-enriched gas mixtures on metabolic rate during exercise. Med Sci Sports 1974; 6: $26-32$

[19] Wilson BA, Welch HG, Liles JN. Effects of hyperoxic gas mixtures on energy metabolism during prolonged work. J Appl Physiol 1975; 39: 267-271

[20] Stellingwerff T, Leblanc P], Hollidge MG et al. Hyperoxia decreases muscle glycogenolysis, lactate production, and lactate efflux during steady-state exercise. Am J Physiol Endocrinol Metab 2006; 290: E1180-E1190

[21] Hughson, Kowalchuk JM Kinetics of oxygen uptake for submaximal exercise in hyperoxia, normoxia, and hypoxia. Can J Appl Physiol 1995; 20: $198-210$

[22] Schaeffer MR, Ryerson C], Ramsook AH et al. Effects of hyperoxia on dyspnoea and exercise endurance in fibrotic interstitial lung disease. Eur Respir J 2017; 49: 1602494

[23] Amann M, Eldridge MW, Lovering AT et al. Arterial oxygenation influences central motor output and exercise performance via effects on peripheral locomotor muscle fatigue in humans. J Physiol 2006; 575: 937-952

[24] Allen PD, Pandolf KB. Perceived exertion associated with breathing hyperoxic mixtures during submaximal work. Med Sci Sports 1977; 9: 122-127

[25] Peeling P, Andersson R. Effect of hyperoxia during the rest periods of interval training on perceptual recovery and oxygen re-saturation time. J Sports Sci 2011; 29: 147-150

[26] Plet J, Pedersen PK, Jensen FB et al. Increased working capacity with hyperoxia in humans. Eur J Appl Physiol 1992; 65: 171-177

[27] Bak Z, Sjöberg F, Rousseau A et al. Human cardiovascular dose-response to supplemental oxygen. Acta Physiol (Oxf) 2007; 191: 15-24

[28] Gole Y, Gargne O, Coulange M et al. Hyperoxia-induced alterations in cardiovascular function and autonomic control during return to normoxic breathing. Eur J Appl Physiol 2011; 111: 937-946

[29] Harriss DJ, MacSween A, Atkinson G. Ethical standards in sport and exercise science research: 2020 update. Int J Sports Med 2019; 40: 813-817

[30] Steinberg F, Dräger T, Steegmanns A et al. fit2dive-A field test for assessing the specific capability of underwater fin swimming with SCUBA. Int J Perform Anal Sport 2011; 11: 197-208

[31] Borg GAV. Psychophysical bases of perceived exertion. Med Sci Sports Exerc 1982; 14: 377-381
[32] Bischoff MM, Duffin J. An aid to the determination of the ventilatory threshold. Eur J Appl Physiol 1995; 71: 65-70

[33] Cohen J. Statistical Power Analysis for the Behavioral Sciences. Hillsday MI: Lawrence Erlbaum Association 1988

[34] Bosco G, Rizzato A, Moon RE et al. Environmental physiology and diving medicine. Front Psychol 2018; 9: 72

[35] Zander R. Oxygen solubility in normal human blood. In: Kovách AGB, Dóra E, Kessler M et al., Eds. Advances in Physiological Sciences: Oxygen Transport to Tissue. $1^{\text {st }}$ Edition. New York: Pergamon Pres; 1981: 331-332

[36] Sperlich B, Schiffer T, Hoffmann U et al. The spirografic oxygen deficit: its role in cardiopulmonary exercise testing. Int J Sports Med 2013; 34: 1074-1078

[37] Mallette MM, Stewart DG, Cheung SS. The effects of hyperoxia on sea-level exercise performance, training, and recovery: A meta-analysis. Sports Med 2018; 48: 153-175

[38] Prieur F, Benoit H, Busso T et al. Effects of moderate hyperoxia on oxygen consumption during submaximal and maximal exercise. Eur J Appl Physiol 2002; 88: 235-242

[39] Macdonald M, Pedersen PK, Hughson RL. Acceleration of VO2 kinetics in heavy submaximal exercise by hyperoxia and prior high-intensity exercise. J Appl Physiol (1985) 1997; 83: 1318-1325

[40] Kane DA. Lactate oxidation at the mitochondria: A lactate-malateaspartate shuttle at work. Front Neurosci 2014; 8: 366

[41] Byrnes WC, Mihevic PM, Freedson PS et al. Submaximal exercise quantified as percent of normoxic and hyperoxic maximum oxygen uptakes. Med Sci Sports Exerc 1984; 16: 572-577

[42] Hogan MC, Cox RH, Welch HG. Lactate accumulation during incremental exercise with varied inspired oxygen fractions. J Appl Physiol Respir Environ Exerc Physiol 1983; 55: 1134-1140

[43] Cardinale DA, Ekblom B. Hyperoxia for performance and training. J Sports Sci 2018; 36: 1515-1522

[44] Pedersen PK, Kiens B, Saltin B. Hyperoxia does not increase peak muscle oxygen uptake in small muscle group exercise. Acta Physiol Scand 1999; 166: 309-318

[45] Linossier MT, Dormois D, Arsac L et al. Effect of hyperoxia on aerobic and anaerobic performances and muscle metabolism during maximal cycling exercise. Acta Physiol Scand 2000; 168: 403-411 